Provided for non-commercial research and education use. Not for reproduction, distribution or commercial use.

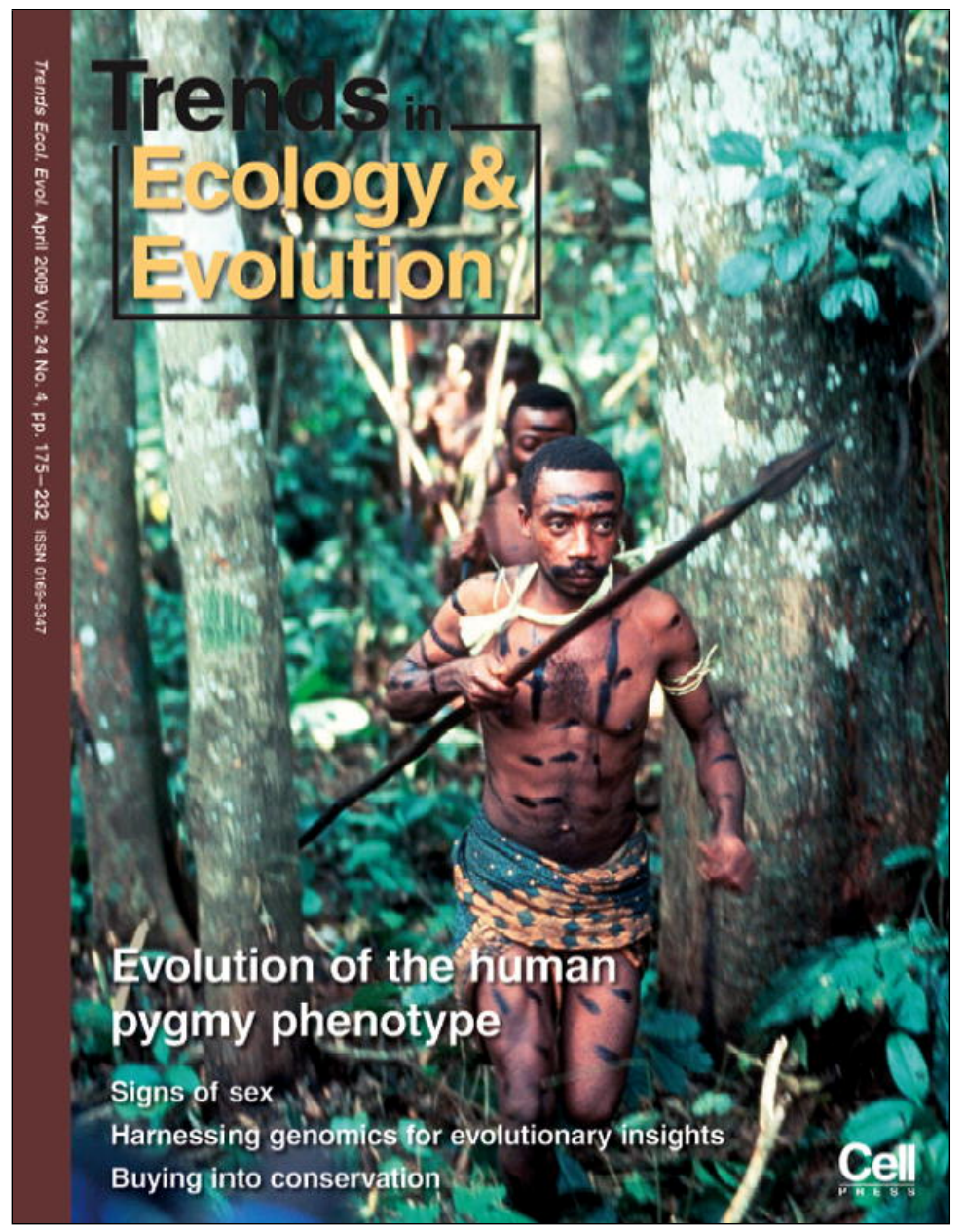

This article appeared in a journal published by Elsevier. The attached copy is furnished to the author for internal non-commercial research and education use, including for instruction at the authors institution and sharing with colleagues.

Other uses, including reproduction and distribution, or selling or licensing copies, or posting to personal, institutional or third party websites are prohibited.

In most cases authors are permitted to post their version of the article (e.g. in Word or Tex form) to their personal website or institutional repository. Authors requiring further information regarding Elsevier's archiving and manuscript policies are encouraged to visit:

http://www.elsevier.com/copyright 


\title{
Buying into conservation: intrinsic versus instrumental value
}

\author{
James Justus ${ }^{1,2}$, Mark Colyvan' ${ }^{2}$, Helen Regan ${ }^{3}$ and Lynn Maguire ${ }^{4}$ \\ ${ }^{1}$ Philosophy Department, Florida State University, Tallahassee, FL 32306, USA \\ ${ }^{2}$ Philosophy Department, University of Sydney, Sydney, NSW 2006, Australia \\ ${ }^{3}$ Biology Department, University of California, Riverside, Riverside, CA 92521, USA \\ ${ }^{4}$ Nicholas School of the Environment, Duke University, Durham, NC 27708-0328, USA
}

\begin{abstract}
Many conservation biologists believe the best ethical basis for conserving natural entities is their claimed intrinsic value, not their instrumental value for humans. But there is significant confusion about what intrinsic value is and how it could govern conservation decision making. After examining what intrinsic value is supposed to be, we argue that it cannot guide the decision making conservation requires. An adequate ethical basis for conservation must do this, and instrumental value does it best.
\end{abstract}

\section{An ethical rationale for conservation decisions}

Conservation biologists often argue natural entities (e.g. non-human species, ecosystems) should be attributed intrinsic value to secure a compelling ethical rationale for their protection. Soulé [1] states that 'biotic diversity has intrinsic value irrespective of its instrumental or utilitarian value,' and claims this is a necessary normative principle of conservation biology. Noss and Cooperrider [2] similarly assert that intrinsic values...offer the least biased and ultimately most secure arguments for conservation,' and McCauley [3] recently invoked the concept of intrinsic value to criticize conservation actions based on monetization of ecosystem services. Given its currency among conservation biologists, clarity about intrinsic value and its efficacy as an ethical basis for conservation is imperative.

\section{What is intrinsic value and what has intrinsic value?}

Ascribing intrinsic value to non-human natural entities is intended to underscore reverence for nature by according them a value independent of humans, thereby liberating humans from narrow anthropocentrism about value. Accordingly, conservation biologists have attributed intrinsic value to a broad range of things. One way of clarifying a concept is to search for patterns in the things to which it is applied. No pattern is apparent in the use of the term 'intrinsic value' in conservation biology. It has been attributed to ecosystems [4,5], all biological entities and their environments [6], wilderness [7,8], wasteland habitats and wild organisms [9], genetic variation that increases probability of population persistence [10] and even all entities produced by natural processes [4]. The apparent lack of any unifying principle underlying these

Corresponding author: Justus, J. (jjustus@fsu.edu). attributions shows that the use of intrinsic value in conservation biology requires scrutiny.

One way to determine which entities of conservation interest have intrinsic value is to appeal to traditional ethical theories originally developed to govern human action. These theories argue that the properties of pleasure, rationality or virtuous character, and entities possessing them, are intrinsically valuable [11]. For example, humans and other sentient organisms that experience pleasure have intrinsic value according to one theory, whereas only humans can exhibit rationality or virtuous character and thus have intrinsic value according to other theories. By analogy, entities of conservation interest could be considered intrinsically valuable if they possessed at least one of these intrinsically valuable properties.

Except sentient animals, however, non-human natural entities that are legitimate targets of conservation (e.g. plants, ecosystems) do not possess any properties considered intrinsically valuable by traditional ethical theories. Some nontraditional theories accord these entities intrinsic value, but such theories are not widely accepted and remain highly controversial [12]. Proponents of intrinsic value in conservation biology therefore need a defensible account of the concept that allows these entities to possess it, and an argument showing they do. Besides unhelpful allusions - that an intrinsically valuable entity is valuable in itself or as an end in itself [13,14], valuable in the absence of humans and other intelligent organisms [6] or of priceless and/or infinite value [3] - explicit descriptions of what intrinsic value is and a convincing account of why non-human natural entities have it have not been given. The above characterizations are not compatible or defensible, and they do not provide workable criteria for determining which entities are intrinsically valuable. Unsurprisingly, articles discussing intrinsic value published in scientific journals often fail to define the concept explicitly (e.g. $[4,6])$.

\section{What is instrumental value?}

Instead of saying what intrinsic value is, attempts to clarify the concept often focus on what it is not, namely, instrumental value. Entities with instrumentally valuable properties are valuable to the extent they are or will be considered valuable by valuers, such as humans and perhaps other cognitively complex organisms. For example, great art is instrumentally valuable because experiencing 
Table 1. Sources of instrumental value of biodiversity

\begin{tabular}{|ll|}
\hline Instrumental value source & Refs \\
\hline Aesthetic & Chapin et al. [26] \\
Ecological and/or ecosystem services & $\begin{array}{l}\text { Hunter and Gibbs [14] } \\
\text { Chapin et al. [26] }\end{array}$ \\
Medical, recreational, tourist & Noss and Cooperrider [2] \\
& McCauley [3] \\
Educational & Hunter and Gibbs [14] \\
Existence & Alexander [23] \\
Scientific & Metrick and Weitzman [27] \\
& Jepson and Canney [28] \\
Spiritual & Hunter and Gibbs [14] \\
& Chapin et al. [26] \\
\hline
\end{tabular}

it is aesthetically and emotionally pleasurable. Art is instrumentally, not intrinsically, valuable because its value is dependent on and derives from the responses it produces in humans (e.g. pleasure). If experiencing a work of art ceased to produce these responses, if it no longer produced pleasure, for example, the art would lose its instrumental value.

Different properties of an entity can be valuable for different reasons, so instrumental value has a wide variety of different sources (Table 1). Given its diverse sources, market-based assessments of an entity's instrumental value can be inappropriate, favoring those that can be evaluated with well-developed economic methods (e.g. natural resources, ecosystem services, visitor admission revenues) over those whose market value is more difficult to assess (e.g. aesthetic, cultural, educational, scientific value). Monetary measures in particular might not accurately represent these diverse sources of value, and thus the instrumental value of an entity should not be narrowly equated with its monetary value. Because it is inappropriate to equate instrumental and monetary value, any antipathy toward instrumental value derived from an antipathy toward monetary value is therefore undeserved. Similarly, concluding that only intrinsic value provides an adequate basis for conservation because monetary value cannot do so is invalid (e.g. [3,13]).

Labeling as 'intrinsic' values that markets find difficult to quantify, but that depend upon and derive from valuers such as humans, misrepresents the integral role these instrumental values have in conservation decision making. Once the mistaken conflation of instrumental value with monetary value is corrected, the diverse sources of instrumental value provide the best ethical basis for conservation. Before making this case, we turn first to problems with intrinsic value.

\section{Decisions require tradeoffs}

Unlike most concepts in conservation biology, intrinsic value is more a philosophical idea than a scientific one. In philosophy, it has been criticized on several grounds [12], including whether a clear distinction between intrinsic and instrumental value can even be drawn [15]. Our criticism, however, is more pragmatic: the intrinsic value of non-human natural entities has no place in the decision support methods successfully used to address conservation problems (e.g. [16]). These methods aid decision making where stakeholders make multiple, often incompatible, claims on resources of conservation interest (e.g. land, water). Such claims depend upon competing sociopolitical, cultural and economic instrumental values that must be reconciled with conservation goals via value tradeoffs. For example, the International Whaling Commission's decision in 2007 to allow Alaskan Eskimos to hunt bowhead whales with traditional methods involved assessing the nutritional and cultural value of subsistence hunts against the potentially negative effects on whale populations. Conservation decision making requires enough articulation and precision about values to weigh them in negotiations. Because instrumental values are ultimately determined by explicit stakeholder valuation, such as from indigenous peoples, governments, conservation advocates and representatives of other interested parties, this assessment is possible. Formal methods such as well-developed multi-attribute value and utility theories (Box 1), costbenefit and cost-effectiveness analyses, heuristic multidimensional optimization algorithms and behavioral methods such as negotiation [17] help make determining the appropriate weighting of instrumental values tractable.

\section{Intrinsic values of non-human entities cannot be measured, prioritized or traded off}

Unlike instrumental value, characterizations of intrinsic value in the conservation literature suggest it is valuer independent and thus independent of stakeholder valuation. It therefore seems to have no role in these decision

Box 1. Decision support methods for conservation: multiattribute decision theory

Multi-attribute decision theory recognizes that decisions need to be made involving competing goals $[24,25]$. Decisions about conservation are no exception [16]. Consider the competing goals of minimizing greenhouse emissions, maximizing biodiversity and minimizing cost. Achieving the first two can be expensive and require conflicting actions. Several methods have been developed to help make these decisions. The central idea in all such methods is to identify the competing values involved and make tradeoffs between them. Standard decision theory requires a common value currency, such as money, but multi-criteria approaches recognize a plurality of currencies (e.g. degree of preference satisfaction, utility, value) and seek appropriate exchange rates between them. For example, how much biodiversity loss should be tolerated for a specific greenhouse gas reduction? One answer from standard decision theory involves developing a function representing total utility that includes the individual utilities produced by reducing greenhouse gas and preventing biodiversity loss, and which specifies the value tradeoffs between the two. An additive linear utility function - such as $U=G+B$, where $U$ represents total utility and $G$ and $B$ represent the utilities derived from reducing greenhouse gas and preventing biodiversity loss - specifies such a value tradeoff. A multiplicative utility function such as $U=G \times B$ specifies a different tradeoff. For multi-attribute decision theory, instrumental values with different types of sources (Table 1) are treated as distinct and measured on separate scales, but are not thought to be incommensurable. Indeed, if they were incommensurable, their comparison and the required tradeoffs would be impossible. Intrinsic value has in fact been called 'priceless' [3], which suggests it is incommensurable with instrumental values. The few other explicit characterizations of intrinsic value in the conservation literature support this view $[6,13,14]$. These claims require explanation and defense, of course, but the suggestion that intrinsic value is incommensurable with other values shows that intrinsic value is unanalyzable within the decision-theoretic methods successfully utilized in conservation decision making. 
frameworks. The problem is that little guidance has been provided about which values should take what degree of priority when intrinsic and instrumental values, or intrinsic values of different entities, are offered to justify conflicting conservation actions. But precisely this guidance is required to reconcile opposing values in conservation decision making to determine an ethical rationale for conservation and achieve conservation goals.

Considering conflicts between intrinsic and instrumental values first, it is important to recognize that such conflicts are not hypothetical. The intrinsic value of nonhuman entities has been asserted to have priority over actions that achieve sociopolitical and cultural instrumental values in discussions of biodiversity conservation (e.g. [18]). The past strategy to conserve tigers in India by forcibly removing indigenous people from their homelands is arguably an example of the intrinsic value of non-human organisms being taken to trump the sociocultural values of those displaced [19]. Particularly troublesome is the idea that intrinsic value is infinite, as McCauley [3] claims. This would have disastrous consequences for conservation: entities with infinite value would require protection even if it meant destroying everything else of (merely finite) instrumental value. With little clarity about what is meant by intrinsic value and without a cogent account of how intrinsic and instrumental values can be compared in a decision context, which seems unlikely given the lack of a connection between stakeholder valuation and intrinsic value, intrinsic value cannot have a role in conservation decision making.

Similar worries beset actions that would produce conflicts between assessments of the intrinsic values of different entities. Many conservation goals require tradeoffs where some entities are protected to the detriment of others. For instance, ensuring ecosystem persistence can require culling species [20]. Most intrinsic value proponents claim all species and ecosystems are intrinsically valuable, but offer little guidance about how considering their intrinsic value resolves such conflicts. One exception is the claim that once one accepts 'the idea of intrinsic value, it is relatively straightforward to decide which species merit more attention from conservation biologists: they are those species most threatened with extinction' [14]. This suggestion provides little guidance, because limited resources mean many threatened species cannot be saved and tradeoffs are unavoidable. Worse still, human-held values produce taxonomic biases in conservation research [21] that typically prejudice determination of which species are most endangered. Thus, even on this intrinsic value platform, only species that generate sufficient (instrumental) interest in acquiring information about them can be determined to have high extinction risk. Intrinsic value arguments inevitably rely on instrumental values for implementation.

A rare, commendably explicit attempt to quantify the intrinsic value of non-human entities illustrates these problems. Despite the fact that the US Endangered Species Act (ESA) and subsequent judicial decisions never mention 'intrinsic value,' Callicott [13] claims the ESA 'express[es] a noninstrumental, deontological [i.e. intrinsic] concern for biodiversity.' On this basis, Callicott theorizes a general principle for quantifying intrinsic value: penalties imposed by democratic legislation reflect differences in the intrinsic value of the subject of the legislation. For example, fines and imprisonment for violating biodiversity protection laws, or life imprisonment for murder, would indicate different degrees of intrinsic value of biodiversity and human life, respectively. Legislative assessments of value expressed by penalties would then estimate quantities of intrinsic value.

This argument has serious difficulties. First, perversion of legislative processes by campaign contributions, lobbyists and more generally those with power in democracies seems to undermine the ability of legislation to legitimately reflect intrinsic value. Second, different sociopolitical and cultural contexts lead the legislatures of different countries to impose a dramatic diversity of penalties, which raises difficulties for the idea that the penalties reflect valuer-independent intrinsic value. The fundamental problem, however, is that no theory of intrinsic value for non-human natural entities is given by which the accuracy of 'democratic objectification of what should or should not be accorded intrinsic value' [13] can be evaluated. Without an independent, compelling theory, when and how accurately legislation reflects degrees of intrinsic value is unclear. Without such a theory, it is also mysterious how complex political deal making among elected representatives (and non-elected parties) achieves privileged insight into intrinsic value, whereas direct assessment of stakeholders' valuations merely provides information about instrumental value. As such, claims that legislation estimates degrees of intrinsic value are untestable.

For instrumental values, no analogous problem exists. Based on information from stakeholders, such as information elicited in surveys, group negotiations or through more structured methods like the analytic hierarchy process [22], instrumental values relevant to specific conservation decisions can be categorized and prioritized, sometimes in monetary terms, but often not (as in costeffectiveness analysis or multi-attribute utility analysis [Box 1]). By contrast, intrinsic values are independent of, and thus presumably not constrained by, such information. Whether a non-human natural entity possesses intrinsic value and to what degree is therefore unclear. Without methods for measuring, trading off or prioritizing the intrinsic value of non-human natural entities, the concept provides an inadequate basis for conservation decision making and thus a poor ethical foundation for conservation. The ability of instrumental value to do so, however, has been underappreciated.

\section{Instrumental value fully appreciated}

Theoretical difficulties with intrinsic value are the focus of philosophical debates $[12,15]$, and these seemingly irresolvable debates would routinely arise in conservation decision making if intrinsic value were its appropriate ethical focus, precluding the formulation of clear and compelling justifications for conservation against competing interests. Focusing on instrumental values does not share these difficulties. Despite its negative connotation in conservation, instrumental value is simply value that depends on valuers. It has a broad range of sources (Table 1) and 
should not be confused with market value (although market valuation of environmental resources like clean water has motivated some notable conservation successes), nor denigrated as implying entities are only valuable as instruments for human manipulation.

Freed from these misconceptions, the indispensability of instrumental value in conservation decision making is obvious. Choosing the best strategies for achieving conservation goals requires weighing options and identifying those maximizing the values involved. Appealing exclusively to market-based measures of value is not the only or even most effective way of proceeding. A forest's instrumental value is not just its current economic value any more than a great painting's value should be narrowly equated with the cost of materials and artist's time, or even its auction price. For example, a forest might be aesthetically valuable to those individuals who experience it, even if they cannot or would not for whatever reason pay for its preservation in a market. Similarly, a forest might also contain unique biological processes that would shed light on a contentious scientific hypothesis if studied properly, even if the scientists who value the study are unable to pay for the forest's preservation. In both cases, the value involved would not exist if the forest aesthetes or scientists did not value the forest. Intrinsic value appears attractive to conservation biologists primarily because it seems to justify claims that the value of entities of conservation interest transcends economic valuation. But intrinsic value need not be invoked for this task; recognizing nonmonetary instrumental value such as aesthetic, cultural, scientific and existence value - the value an entity has merely because its continued existence is valued [23] - is sufficient.

Indeed, instrumental values seem to offer the only viable means of conservation decision making. On the one hand, focusing on the intrinsic value of non-human natural entities requires an as yet undeveloped standard of value analysis for which no convincing methodology (or theoretical basis) has been formulated. On the other hand, focusing on instrumental values allows conservation decisions to be analyzed with the same tools as other decisions with multiple, sometimes conflicting, goals: all instrumental value is comparatively assessed without one form taking absolute priority. Rather than 'selling out on nature,' as McCauley [3] puts it, we view this approach as 'buying into conservation.'

Admittedly, there are challenges. That values are instrumental does not mean accessing and measuring them is straightforward. Knowing what stakeholders prefer, and how strongly, is often difficult but not impossible. Similarly, measuring instrumental value from different sources can be difficult, as can reconciling different stakeholder values and determining which are relevant for specific decisions. Various solutions to these problems tradeoff analyses for the former and social choice methods for the latter - have been rigorously studied in decision sciences and applied to conservation decision making [16] (Box 1). Nothing similar exists in intrinsic value literature.

Some of this debate might be terminological. Non-market instrumental values are sometimes labeled intrinsic in the conservation literature. Nonetheless, the dispute is not merely terminological. We believe intrinsic value advocates are correct to argue that market-based assessments of instrumental value alone provide an inadequate basis for conservation decision making. But this does not necessitate embracing intrinsic value rather than a broad conception of instrumental value. Treating some forms of instrumental value as intrinsic generates misunderstanding by obscuring the crucial role in conservation decision making and ethical importance of instrumental values that are not traded in markets. It also obscures why many individuals become conservation biologists. Their motivation often stems from the beauty, scientific curiosity, emotional connection and feeling of obligation to future generations catalyzed by biodiversity. The values underlying these sentiments are instrumental, not intrinsic. They are no less profound or psychologically potent for being so.

\section{Acknowledgements}

This work was conducted as part of the Decision Making for Complex Environmental Problems Working Group supported by the National Center for Ecological Analysis and Synthesis (NCEAS), a center funded by the NSF (grant DEB-0553768), the University of California-Santa Barbara and the State of California. We also acknowledge the support of the Australian Commonwealth Environment Research Facilities Research Hub for Applied Environmental Decision Analysis (AEDA). We have benefited greatly from discussions with group participants, and are also indebted to Tracey Regan, Carl Salk, Rebecca Swab and three reviewers for helpful comments.

\section{References}

1 Soulé, M.E. (1985) What is conservation biology? Bioscience 35, 727734

2 Noss, R. and Cooperrider, A.R. (1994) Saving Nature's Legacy. Island Press

3 McCauley, D.J. (2006) Selling out on nature. Nature 443, 27-28

4 Angermeier, P.L. (2000) The natural imperative for biological conservation. Conserv. Biol. 14, 373-381

5 Wilson, E.O. (1992) The Diversity of Life. Harvard University Press

6 Redford, K.H. and Richter, B.D. (1999) Conservation of biodiversity in a world of use. Conserv. Biol. 13, 1246-1256

7 Chambers, J.Q. et al. (2001) Carbon sink for a century. Nature 410, 429

8 Noss, R. (1991) Sustainability and wilderness. Conserv. Biol. 5, 120 122

9 Harrison, C. and Davies, G. (2002) Conserving biodiversity that matters: practitioners' perspectives on brownfield development and urban nature conservation in London. J. Environ. Manage. 65, 95-108

10 Pearman, P. (2001) Conservation value of independently evolving units: sacred cow or testable hypothesis? Conserv. Biol. 15, 780-783

11 Jamieson, D. (ed.), (2000) A Companion to Environmental Philosophy, Blackwell

12 Grey, W. (1993) Anthropocentrism and deep ecology. Australas. J. Philos. 71, 463-475

13 Callicott, J.B. (2006) Explicit and implicit values. In The Endangered Species Act at Thirty (Scott, J.M. et al., eds), pp. 36-48, Island Press

14 Hunter, M.L., Jr and Gibbs, J. (2007) Fundamentals of Conservation Biology. (3rd edn), Blackwell Publishing

15 Feldman, F. (1998) Hyperventilating about intrinsic value. J. Ethics 2, 339-354

16 Moffett, A. and Sarkar, S. (2006) Incorporating multiple criteria into the design of conservation area networks: a minireview with recommendations. Divers. Distrib. 12, 125-137

17 Burgman, M. (2005) Risks and Decisions for Conservation and Environmental Management. Cambridge University Press

18 Rolston, H., III (1999) Respect for life: counting what Singer finds of no account. In Peter Singer and His Critics (Jamieson, D., ed.), pp. 247 268, Blackwell

19 Guha, R. and Martinez-Alier, J. (1998) Varieties of Environmentalism: Essays North and South. Oxford University Press 
20 Myers, J.H. et al. (2000) Eradication revisited: dealing with exotic species. Trends Ecol. Evol. 15, 316-320

21 Clark, J.A. and May, R.M. (2000) Taxonomic biases in conservation research. Science 297, 191-192

22 Saaty, T.L. (2005) The analytic hierarchy and analytic network processes for the measurement of intangible criteria and for decision-making. In Multiple Criteria Decision Analysis: State of the Art Surveys (Figueira, J. et al., eds), pp. 345-407, Kluwer

23 Alexander, R.R. (2000) Modeling species extinction: the case for nonconsumptive values. Ecol. Econ. 35, 259-269
24 Dyer, J. (2005) MAUT - multiattribute utility theory. In Multiple Criteria Decision Analysis: State of the Art Surveys (Figueira, J. et al., eds), pp. 265-294, Kluwer

25 Keeney, R.L. and Raiffa, H. (1993) Decisions with Multiple Objectives: Preferences and Value Tradeoffs. Cambridge University Press

26 Chapin, F.S., III et al. (2000) Consequences of changing biodiversity. Nature 405, 234-242

27 Metrick, A. and Weitzman, M.L. (1998) Conflicts and choices in biodiversity preservation. J. Econ. Perspect. 12, 21-34

28 Jepson, P. and Canney, S. (2001) Biodiversity hotspots: hot for what? Glob. Ecol. Biogeogr. 10, 225-227

\section{Forthcoming Conferences}

Are you organizing a conference, workshop or meeting that would be of interest to TREE readers? If so, please e-mail the details to us at TREE@elsevier.com and we will feature it in our Forthcoming Conference filler.

\section{2-7 August 2009}

94th ESA Annual Meeting, Albuquerque, NM, USA

http://www.esa.org/albuquerque/

16-21 August 2009

10th International Congress of Ecology, Brisbane,

Australia

http://www.intecol10.org/

17-21 August 2009

Ecological/Biological, Stoichiometry Workshop for

Young Scientists, Tohoku, Japan

http://meme.biology.tohoku.ac.jp/woodstoich/

Woodstoich\%202009.html

21-26 August 2009

7th Conference of the European Ornithologists' Union

2009, Zurich, Switzerland

http://www.eou2009.ch/

\section{4-29 August 2009}

12th Congress of the European Society for

Evolutionary Biology, Torino, Italy

http://www.eseb2009.it/uk/

8-12 September 2009

7th Cold Spring Harbor meeting on Microbial

Pathogenesis and Host Response, Cold Spring Harbor

NY, USA

http://meetings.cshl.edu/meetings/host09.shtml

8-10 September 2009

BES Annual Meeting 2009

http://www.britishecologicalsociety.org/articles/ meetings/current/2009annualmeeting/

23-26 September 2009

69th Society of Vertebrate Paleontology Annual Meeting, Bristol, UK

http://www.vertpaleo.org/meetings/index.cfm

27-30 October 2009

9th Cold Spring Harbor Laboratory/Wellcome Trust conference on Genome Informatics, Cold Spring Harbor, NY, USA

http://meetings.cshl.edu/meetings/info09.shtml 